\title{
Science and Policy
}

\section{Initiative for an International Panel on Chemical Pollution (IPCP)}

\author{
Martin Scheringer ${ }^{1 *}$, Heidelore Fiedler ${ }^{2}$, Noriyuki Suzuki ${ }^{3}$, Ivan Holoubek ${ }^{4}$, Cornelius Zetzsch ${ }^{5}$ and Åke Bergman ${ }^{6}$ \\ ${ }^{1}$ Gruppe für Umwelt- und Sicherheitstechnologie, Institut für Chemie- und Bioingenieurwissenschaften, ETH Hönggerberg, HCI G 127, \\ 8093 Zürich, Switzerland \\ 2 UNEP Chemicals Branch, DTIE International Environment House , 11-13, Chemin des Anémones, 1219 Châtelaine (GE), Switzerland \\ ${ }^{3}$ Exposure Assessment Research Section, Research Center for Environmental Risk, National Institute for Environmental Studies, \\ 16-2 Onogawa, Tsukuba, Ibaraki 305-8506, Japan \\ ${ }^{4}$ Masaryk University, RECETOX, Kamenice 126/3, 62500 Brno, Czech Republic \\ ${ }^{5}$ BayCEER, Universität Bayreuth, Forschungsstelle für Atmosphärische Chemie, Dr. Hans-Frisch-Str. 1-3, 95448 Bayreuth, Germany \\ ${ }^{6}$ Department of Environmental Chemistry, Stockholm University, 10691 Stockholm, Sweden
}

*Corresponding author (scheringer@chem.ethz.ch $)$

\section{DOI: http://dx.doi.org/10.1065/espr2006.09.347}

At the 2006 Dioxin Conference in Oslo, an Open Meeting was held on Managing risks of global POPs contamination: Do we need an Intergovernmental Panel on Chemical Pollution as a new global framework? The purpose of the meeting was to discuss the proposal for an Intergovernmental Panel on Chemical Pollution, IPCP, that was originally presented by M. Scheringer at the 2004 Dioxin Conference in Berlin.

MARTIN SCHERINGER opened the meeting with an introduction of the IPCP proposal. The problem that makes an IPCP desirable includes several aspects: (i) scientific knowledge about sources, fate and effects of chemicals in the environment is often fragmented and incomplete, (ii) high uncertainties impede the use of scientific results in decision making processes, and (iii) support and funding for research into many aspects of chemical pollution is insufficient.

The main task of an IPCP would be to deal with these difficulties at a global level. The IPCP would address transboundary pollution by chemicals undergoing long-range transport, in particular persistent organic pollutants (POPs), but also local pollution problems occurring in a similar way in several countries so that an exchange of knowledge and technology is needed.

Ideally, the IPCP would provide scientific support for politics but also political support for the science. Scientific support for politics includes that scientists working with the IPCP would compile and evaluate existing results of research into transboundary chemical pollution, that databases are established so that various types of data can be harmonized and shared (emission inventories, chemical properties, monitoring data); that evaluated results are provided for decision makers, for example in the form of official reports on priority issues, and that the IPCP participates as a scientific stakeholder in the process of political consensus building that is a prerequisite for concrete action on a particular problem. Political support for the scientific research into chemical pollution would mean that awareness is created among the public and policy makers, that research in priority areas such as measurements of chemical properties and monitoring programs is internationally coordinated, and that emphasis is put on fields which are not part of the scientific mainstream but are needed for our understanding of the sources, fate and effects of chemicals in the environment.

A first step in establishing an IPCP is that the relationship between the IPCP and existing institutions is defined. There are several international institutions working at the interface between science and politics; the point of the IPCP proposal is not to replace these institutions or to repeat their work. The purpose of the IPCP is to increase this type of effort in order to further improve the interface between science and politics. To be defined are the relationships between the IPCP and, among other, the following institutions: the Intergovernmental Forum on Chemical Safety, the International Programme on Chemical Safety, the European Monitoring and Evaluation Programme, the Arctic Monitoring and Assessment Programme, and the European Environment Agency.

A particular aspect is the relationship between the IPCP and the Stockholm Convention on Persistent Organic Pollutants. A first mandate of the IPCP could be to support the implementation of the Stockholm Convention but the mandate of the IPCP could also be broader.

After this outline of possible tasks of the IPCP, HeIDELore FIEDLER from UNEP Chemicals, Geneva, focused on the relationship between a future IPCP and the Stockholm Convention on POPs. The Stockholm Convention entered into force on May 17, 2004; presently, there are 128 Parties to the Convention, see www.pops.int. The governing body of the Convention is the Conference of the Parties (COP) with next meetings in 2007 and 2009. The IPCP could participate in the COP meetings and meetings of subsidiary bodies as an observer organization or individual members of the IPCP as a delegate of their respective government(s). There are four options for the IPCP to provide input for the implementation of the Stockholm Convention: 
- Identification of new POPs. The POP Review Committee is responsible for the evaluation of proposals for candidate POPs. After application of screening criteria for possible POPs, a risk profile is established and options for risk management are evaluated. For all of these steps, scientific expertise provided by the IPCP could be useful input.

- Evaluation of the effectiveness of the Stockholm Convention. To evaluate whether the measures taken to reduce releases and levels of POPs are effective, a global monitoring plan is to be developed. An ad hoc technical working group with representatives from the five United Nations regions coordinates the development of the monitoring plan. To support the global monitoring of POPs (selection of sampling sites and sampling methods, interpretation of results, etc.) would exactly be a task that could be addressed by the IPCP as an organization of collaborating scientists from all over the world and all involved scientific fields.

- Research, development and monitoring of POPs, their alternatives and of candidate POPs. The parties to the Stockholm Convention have various responsibilities for, i.e., research into and monitoring of sources and releases of POPs, levels and fate in the environment, effects on human health and the environment, but also socio-economic and cultural impacts, and for release reductions. Again, the coordinated efforts and broad, internationally based expertise to be provided by the IPCP could be a valuable resource for parties in their work under the Stockholm Convention.

- Sub-regional centers for capacity building and technology transfer. The mandate of these centers is to provide capacity-building and to promote the transfer of technology to assist developing country parties and parties with economies in transition to fulfill their obligations under the Stockholm Convention. Such centers may have staff that are member to IPCP or IPCP as an institution could closely cooperate with these centers and provide scientific input for their work.

In conclusion, there are several interfaces by which the IPCP could collaborate with the different bodies of the Stockholm Convention. The work envisaged for the IPCP would cover several important aspects to be dealt with under the Stockholm Convention.

NORIYUKI SUZUKI from the National Institute for Environmental Studies, Japan, stated that there is a need for a sound and consistent scientific support of the global chemical risk assessment and management. This would include, for example, the sharing of data, coordination of research initiatives, and consistent risk communication; the IPCP as a group of scientists collaborating at the global level could be mandated with this task. A starting point for the work of the IPCP could be the problem of persistent organic pollutants because for POPs a global assessment and coordination of efforts is required.

With the IPCP proposal as described above as a starting point, there are several open questions:

- What is the range of topics to be dealt with by the IPCP? Various scientific fields will be relevant to the work of the IPCP, including environmental chemistry in a broad sense but also biological sciences, medicine, engineering sciences and social sciences. Depending on the mandate of the IPCP, it will be important to find representatives from all relevant fields.

- What kind of result will the IPCP provide? Will the IPCP focus on the discussion among scientists and, based on this, provide evaluated summaries of scientific results or will it also give recommendations for policy makers?

- In what way will the IPCP be organized and who will participate in the work of the IPCP? Will the IPCP consider various and also diverging points of view? It is important that the standpoint of the IPCP is as politically neutral and objective as possible and that its results are based on a sound scientific background. At the same time, the large uncertainties of many findings to be evaluated by the IPCP will make it important to consider various scientific opinions and to find a balanced perspective in final statements, clearly pointing out different possible interpretations of uncertain results.

- How will the IPCP find a balance between the scientific interest in exploring open questions and the practical need for making decisions even when there are high uncertainties (scientists are interested in investigating new issues, governments and industry are interested in controlling/resolving issues)? This is again related to the question of how uncertain scientific results will be dealt with; uncertain and incomplete results are a starting point for further research but have at the same time to be used as a basis for decision making.

- In what way will the collaboration with existing institutions be organized? There are many organizations at global and regional levels which also deal with problems of chemical pollution (UNEP, Intergovernmental Forum on Chemical Safety (IFCS), OECD, Strategic Approach to International Chemicals Management (SAICM), NGOs, scientific societies, national governments, etc.) and the relationship between the IPCP and these organizations needs to be defined.

Ivan Holoubek from the Research Center for Environmental Chemistry and Ecotoxicology (RECETOX) at Masaryk University, Brno, Czech Republic, pointed out why valid scientific results about anthropogenic chemicals in the environment are needed:

- Knowledge about levels and trends of chemicals in the environment makes it possible to evaluate how effective measures taken to mitigate exposure and effects actually are.

- An understanding of processes and the environmental fate of chemicals is needed to establish a sufficient understanding of the distribution and pathways of chemicals in the environment.

- Monitoring is needed to observe actual spatial and temporal trends at the regional and global level.

- Models need to be combined with measurements to improve the understanding of the influence of individual processes on the environmental fate of a chemical and of the mass fluxes from sources to receptors.

- Decision making processes at various political levels should be supported by a sound scientific basis. 
However, our current understanding of the global environmental fate of POPs and other chemicals is limited by considerable uncertainties. In the light of these uncertainties, what are the needs?

There are many international programs and activities conducted by many working groups, expert committees and political bodies. Is the degree of co-ordination and collaboration between these many activities sufficient? Is the money used in these activities effectively spent? In various cases, a better and more effective cooperation would be desirable. Here, the IPCP could play a helpful role because it would bring members of various groups into closer contact.

Another need would be more research that is oriented towards targets defined by practical pollution problems. For example, will the 7th EU Framework Programme reflect what kind of knowledge will be needed for the EU to fulfil its obligations under the Stockholm Convention and other chemicalrelated international conventions? Again, the IPCP could help to highlight which areas need scientific investigation and, as a prerequisite, political awareness and financial support.

In conclusion, the IPCP could improve the informal and formal collaboration between scientists active in various international working groups, technical expert groups and political bodies, and it could help to achieve a more consistent picture of the sources, fate and effects of chemicals in the environment and to support further research in the field.

CoRnelius ZetZsCh from the University of Bayreuth, Germany, focused on the field of atmospheric chemistry of semivolatile organic chemicals (SOCs), which include many chemicals of environmental relevance (pesticides, plastic additives etc.). The atmosphere is the most important medium for the transport of many chemicals and also for their degradation by light, $\mathrm{OH}$ radicals, or other agents. The atmospheric chemistry of SOCs determines the chemicals' lifetime, their interaction with atmospheric aerosols and their deposition mass fluxes. Degradation and deposition in combination determine the atmospheric residence time of the chemicals. The residence time, in turn, strongly influences the potential for long-range transport and is therefore a key quantity that should be known with high reliability.

However, the processes determining the atmospheric lifetime of SOCs have not yet been sufficiently investigated; in many cases, the atmospheric fate is only poorly known and lifetimes and potential for transboundary pollution have to be estimated. Accordingly, it is difficult to predict deposition, persistence and long-range transport of SOCs, and available estimates are fraught with considerable uncertainties.

An important task of the IPCP would be to support research into the atmospheric chemistry of SOCs and to make the implications of this research available for decision makers and the public.

In a discussion statement, ÅKE Bergman from Stockholm University, Sweden, pointed out several possible functions of the IPCP. First, similar to the Intergovernmental Panel on Climate Change (IPCC), the IPCP should inform the public and create awareness for issues of chemical pollution. Because chemical pollution has many different aspects, it is important to relate these different aspects to one another and to create a coherent picture and communicate this picture to policy makers and the public. This will also help to identify issues of higher and lower priority.

Second, the work of the IPCP should be driven by the work of and discussion among scientists from all over the world. The IPCP should help to establish a network of scientists contributing their expertise to the process of evaluating scientific findings, identifying major uncertainties and research needs, comparing different interpretations of existing data and drawing conclusions, and making scientific information available in a format that is useful for policy makers and the public.

The work of the IPCP should include pollution problems caused by persistent chemicals but it should not be limited to this group of compounds. Issues related to semi-persistent organic pollutants (SOPs) should be included in the IPCP mandate.

Finally, the IPCP should help to represent scientists as an independent 'stakeholder group' in the political discussion about chemical pollution and in the negotiation processes for international conventions about chemical pollution issues.

After the Open Meeting in Oslo, the authors of this report discussed the name of the institution to be established. To some extent, the Intergovernmental Panel on Climate Change, IPCC, is a model for the IPCP initiative presented here. However, the IPCC was established as an institution that is open to all members of the UN and the World Meteorological Organization, WMO, i.e. members of the IPCC are countries or groups of countries. This is reflected by the term 'intergovernmental' in the name of the IPCC. In contrast, the panel on chemical pollution presented here has its origin in an international network of scientists. Therefore, it was decided to call the panel 'International Panel on Chemical Pollution' in the present stage; members of the panel will be individual scientists. However, it is intended to find support for the panel by governments from countries in all regions of the world and also within the UN. In the case that in a later stage the IPCP is given an official status within the UN, it may change its name to Intergovernmental Panel on Chemical Pollution.

\section{Further information on the scientific and political debate about} POPs can be found in the following contributions in ESPR

Lammel G, Semeena VS, Guglielmo F, Ilyina T, Leip A (2006): Bestimmung des Ferntransports von persistenten organischen Spurenstoffen und der Umweltexposition mittels Modelluntersuchungen. UWSF - Z Umweltchem Ökotox, OnlineFirst <DOI: http://dx.doi.org/10.1065/uwsf2006.09.136>

Scheringer M (2005): Challenges for Environmental Science. Environ Sci Pollut Res 12 (4) 186-187

Scheringer M (2004): Persistent Organic Pollutants (POPs) in the Focus of Science and Politics. Environ Sci Pollut Res 11 (1) 1-2

Scheringer M, Klöpffer W (2001): How to Deal with Persistent Organic Pollutants (POPs)? Environ Sci Pollut Res 8 (1) 63

Scheringer M, Stroebe M, Wania F, Wegmann F, Hungerbühler K (2004): The Effect of Export to the Deep Sea on the Long-Range Transport Potential of Persistent Organic Pollutants. Environ Sci Pollut Res 11 (1) 41-48 (2004) 